See discussions, stats, and author profiles for this publication at: https://www.researchgate.net/publication/228102472

\title{
In vitro activity of human translation initiation factor eIF4B is not affected by phosphomimetic amino acid substitutions S422D and S422E
}

Article in Biochimie · June 2012

Dol: 10.1016/j.biochi.2012.06.021 · Source: PubMed

\section{CITATIONS}

8

5 authors, including:

6.

Lev Shagam

Pirogov Russian National Research Medical University

18 PUBLICATIONS 55 CITATIONS

SEE PROFILE

F. Dmitry Andreev

Lomonosov Moscow State University

84 PUBLICATIONS 1,150 CITATIONS

SEE PROFILE
READS

95

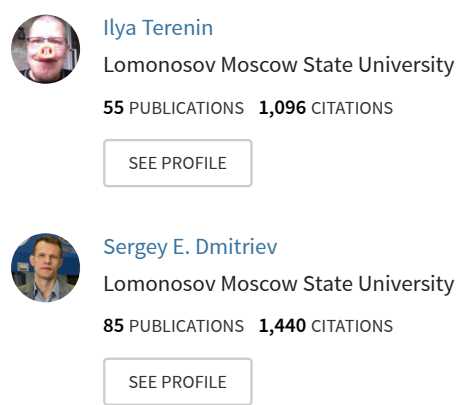

Some of the authors of this publication are also working on these related projects:

Project Translation initiation complex formation on mRNAs with structured leaders View project

Project elF2D and its homologs MCTS1 and DENR in translation initiation, re-initiation and recycling View project 
Provided for non-commercial research and education use. Not for reproduction, distribution or commercial use.

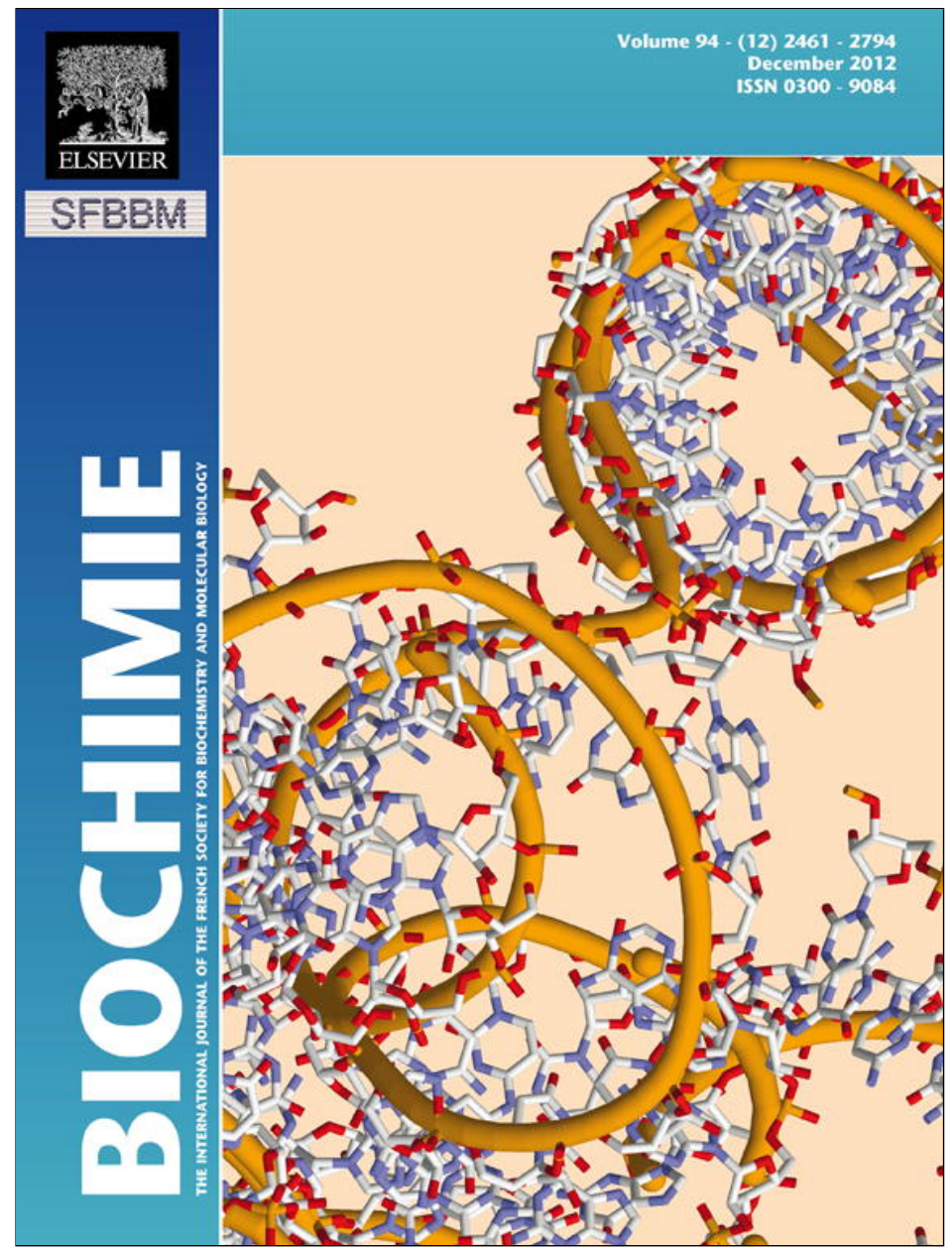

This article appeared in a journal published by Elsevier. The attached copy is furnished to the author for internal non-commercial research and education use, including for instruction at the authors institution and sharing with colleagues.

Other uses, including reproduction and distribution, or selling or licensing copies, or posting to personal, institutional or third party websites are prohibited.

In most cases authors are permitted to post their version of the article (e.g. in Word or Tex form) to their personal website or institutional repository. Authors requiring further information regarding Elsevier's archiving and manuscript policies are encouraged to visit:

http://www.elsevier.com/copyright 
Research paper

\title{
In vitro activity of human translation initiation factor eIF4B is not affected by phosphomimetic amino acid substitutions S422D and S422E
}

\author{
Lev I. Shagam, Ilya M. Terenin, Dmitri E. Andreev, Jacov E. Dunaevsky, Sergey E. Dmitriev* \\ Belozersky Institute of Physico-Chemical Biology, Lomonosov Moscow State University, Bldg. A, Leninskie Gory, Moscow 119234, Russia
}

\section{A R T I C L E I N F O}

\section{Article history:}

Received 1 June 2012

Accepted 20 June 2012

Available online 28 June 2012

\section{Keywords:}

Eukaryotic translation initiation factor eIF4B Phosphorylation

Ser422Glu

Ser422Asp

PIK3/mTOR signaling pathway

48S complex reconstitution

\begin{abstract}
A B S T R A C T
Eukaryotic translation initiation factor eIF4B is necessary for ribosomal scanning through structured mRNA leaders. In higher eukaryotes, eIF4B serves as a downstream effector of several signaling pathways. In response to mitogenic stimuli, eIF4B undergoes multiple phosphorylations which are thought to regulate its activity. Recently, Ser422 was identified as a predominant site for human eIF4B phosphorylation via several signaling pathways, and phosphomimetic amino acid substitutions S422D or S422E were shown to activate eIF4B in living cells. However, stimulatory role of these modifications has never been analyzed directly. Here, using both mammalian reconstituted translation initiation assay and complete cell-free translation system, we perform a comparison of recombinant eIF4B derivatives with the wild type recombinant protein, and do not find any difference in their activities. On the contrary, native eIF4B purified from HeLa cells reveals significantly higher activity in both assays. Thus, the effects of S422D and S422E substitutions on eIF4B activity in living cells observed previously either require some other protein modification(s), or may only be manifested in an intact cell. Our study raises the question on whether the phosphorylation of Ser422 is sufficient for elF4B activation observed upon mitogenic stimulation.
\end{abstract}

(c) 2012 Elsevier Masson SAS. All rights reserved.

\section{Introduction}

In eukaryotic cell, protein synthesis is tightly regulated by posttranslational modifications of several components of translational machinery. Concerted modulation of their activity provides a flexible response to extracellular stimuli $[1,2]$. Two most thoroughly studied examples are Ser51 phosphorylation of eIF2 $\alpha$ subunit and multiple modifications of eIF4E-binding proteins (of which the most famous is 4E-BP1). The $\alpha$ subunit of the mammalian eIF2 is phosphorylated by one of the four specific kinases which are activated upon various types of cell stress [3]. This leads to a rapid sequestration of free eIF2 into "frozen" complexes with eIF2B, a guanine nucleotide exchange factor, and dramatic reduction of total protein synthesis in the cell. On the contrary, hierarchical multiphosphorylation of 4E-BP1 at several Ser and Thr residues in response to activation of mitogenic signaling pathways gradually

Abbreviations: eIF, eukaryotic initiation factor; HCV, Hepatitis C Virus; IRES Internal Ribosome Entry Site; $5^{\prime}$ UTR, 5' untranslated region; Fluc, firefly luciferase; Rluc, Renilla luciferase.

* Corresponding author. Tel.: +7 495 9394857; fax: +7 4959393181.

E-mail address: dmitriev_sergey@genebee.msu.ru (S.E. Dmitriev). decreases affinity of this inhibitor to cap-binding factor eIF4E, and stimulates cap-dependent translation [4]. Beyond these two well known cases, there are many other reports on post-translation modifications that affect activities of translation initiation factors in eukaryotic cells, although most of them are poorly characterized (for review, see [1]).

Mammalian eIF4B is a $70 \mathrm{kDa}$ protein containing two RNAbinding domains $[5,6]$. This factor promotes binding of the $40 \mathrm{~S}$ ribosomal subunit to mRNA during translation initiation $[7,8]$ by direct stimulation of ATP-dependent RNA helicase activity of eIF4A [9-12]. Although this stimulation is thought to constitute the major impact of eIF4B on translation, some other mechanisms of its action may not be excluded. Apart from eIF4A and eIF4F, mammalian eIF4B has been shown to directly interact with p170 subunit of eIF3 [13] and with poly(A)-binding protein PABP [14]. The factor is able to bind two RNA molecules simultaneously [15] and forms a dimer in solution $[13,16]$. One of its RNA binding domains has been proposed to interact with the 18S rRNA [15], while the other one may directly bind mRNA thus providing an additional contact of the $40 \mathrm{~S}$ with the template $[15,17]$, stabilizing the unwound mRNA in a single-stranded conformation [11,18-20] or acting as a "pawl" during unidirectional ribosomal scanning [21]. eIF4B has also eIF4Frecycling activity allowing cap-binding complex to dissociate from 
one mRNA and re-associate with another [22] and, in general, may represent a kind of eIF4A ATPase activating protein needed also for eIF4A removal from the scanning complex after ATP hydrolysis [23].

We have shown previously [24] that in a reconstituted mammalian translation system eIF4B is absolutely required for the $48 \mathrm{~S}$ complex formation with cap-dependent mRNAs that possess even weak secondary structure containing GC pairs. Taking into account that the majority of mammalian mRNAs have relatively long (150-200 nt) leaders with a complex nucleotide composition (see, for example [25],), these results unambiguously indicate that eIF4B is a critically important translation machinery component. Interestingly, a similar conclusion has been drawn recently in another study using yeast translation reconstitution assay [26], despite the fact that yeast mRNAs in general have much simpler leaders [27].

The importance of eIF4B for overall cellular translation efficiency was further corroborated by findings that its inactivation during mitosis (mediated by binding to $14-3-3 \sigma$ [28]) and its cleavage upon induction of apoptosis [14,29] are well correlated with reduction of protein synthesis in cell. Modulation of eIF4B activity by phosphorylation (see below) is also relentlessly accompanied by changes in general translation level (for review, see [30,31]). Finally, siRNA-mediated depletion of eIF4B in mammalian cells [32] or knockout of TIF3 gene that encodes eIF4B in yeast $[33,34]$ both cause defects in protein synthesis, disrupting general and mRNA-specific translational control.

Interestingly, in our previous study we found that eIF4B purified from HeLa cells possessed significantly higher activity in the reaction of $48 \mathrm{~S}$ translation initiation complex assembly than a bacterially expressed protein [24]. It was proposed that the cause of such a difference could be a post-translational modification(s) $[24,35]$. Indeed, large-scale proteomic approaches revealed more than 40 sites of modifications in the human eIF4B, mostly phosphorylation of Ser, Thr and Tyr, but also acetylation of Lys (summarized in HPRD database [36], see http://www.hprd.org). Since 1980s, eIF4B has been well documented to be multiphosphorylated in both mammalian and plant systems [35,37-45], and in the former case, the two major sites of the modification have been identified. In 2004, Raught et al. determined Ser422 as a site of eIF4B phosphorylation in response to stimulation of human HEK293 cells by serum [35], and later, Peng with colleagues [46] and van Gorp et al. [44] found an additional mitogen-regulated site, Ser406. The both sites lie within one of the two RNA-binding domains of eIF4B and are well conserved among vertebrates (Fig. S1).

Ser422 is regarded as the major modification site that is phosphorylated in response to amino-acid refeeding [44] and treatment of serum-starved cells with mitogens such as insulin, epidermal growth factor or phorbol ester PMA [35,44,47-51], or cytokines like IL-3, IFN $\alpha$, IFN $\gamma$ or IFN $\lambda$ [44,52,53]. Ser422 phosphorylation is also increased in response to DNA-damaging agents [54] or during arsenic-induced cell transformation [55], and it also accompanies some virus infections [56,57]. Depending on the conditions, the phosphorylation may be directed by either p70S6K1/2 via PI3K/ mTOR signaling pathway [35], p90RSK1/2 via MAPK cascade $[49,52,53]$ or directly by PKB/Akt [44]. The main pathways involved in eIF4B Ser422 phosphorylation are represented in Fig. 1.

Recently, two amino acid substitutions that mimic Ser422 phosphorylation (S422D and S422E) were reported to enhance eIF4B affinity to the eIF3 complex [49,51] and positively affect expression of reporter cap-dependent mRNAs [51] when eIF4B wt, eIF4B S422D or eIF4B S422E were overexpressed in cultured mammalian cells. In contrast, the mutant eIF4B S422A produced no effect on translation in such an assay [35,44,51]. In the latter case, the non-phosphorylatable protein synthesized in vivo might acquire a low activity similar to the recombinant (non-phosphorylated)

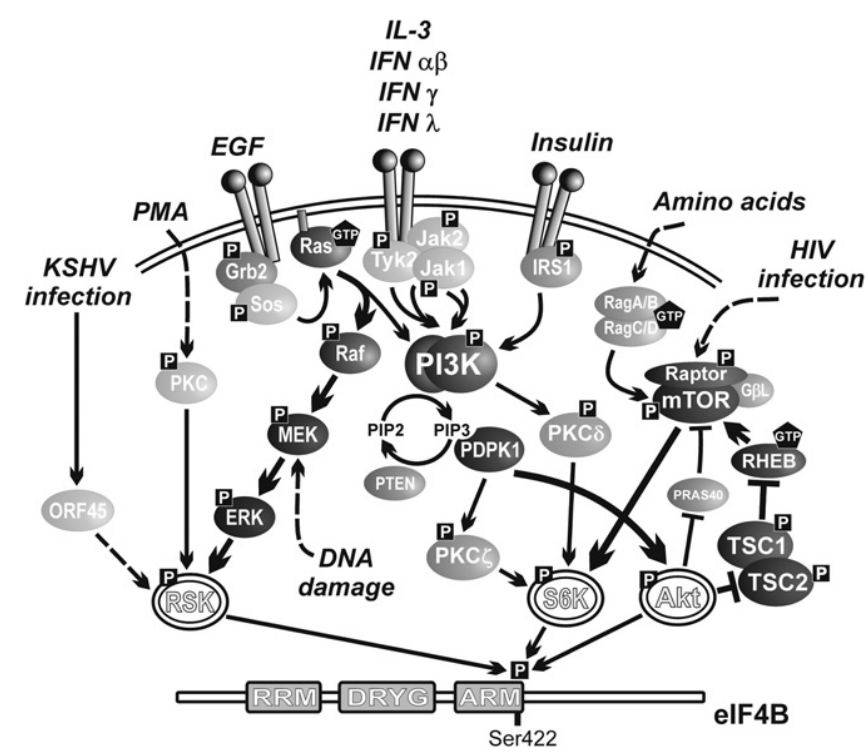

Fig. 1. Signaling pathways involved in phosphorylation of eIF4B Ser422. Kinases that directly phosphorylate Ser422 are double outlined. The main axis of the Ras/MEK/ERK and PI3K/Akt/mTOR pathways are highlighted by thick arrows and dark grey ovals.

protein that we used before in our assay of $48 \mathrm{~S}$ initiation complex assembly in vitro [24]. This suggestion led us to perform a comparison of the recombinant wt and phosphomimetic S422D and S422E proteins activity in the reaction of $48 \mathrm{~S}$ reconstitution from purified components. Here we show that the S422D and S422E eIF4B derivatives have the same activity in this assay as the wt protein, which was lower than the activity of a native eIF4B protein purified from HeLa cells. The same results were obtained also in a complete cell lysate. Our data suggest that Ser422 phosphorylation may be not sufficient for eIF4B activation observed in mammalian cells upon mitogenic stimulation.

\section{Materials and methods}

\subsection{Plasmid constructs and in vitro transcription}

Plasmid pET3b-4B for expression of recombinant human wt eIF4B without any tag in E. coli [58] was kindly provided by W. Merrick (CWRU, Cleveland, Ohio). S422D and S422E substitutions were introduced by PCR-directed mutagenesis with oligonucletide GAGTCATCACAAACTGGGACC as a forward primer and ATCTCCTGTCCTCGACCGTTCC or TTCTCCTGTCCTCGACCGTTCC as reverse ones, respectively. ORF correctness in all three constructs was confirmed by sequencing of the complete coding regions. Plasmid encoded for TPL$\beta$-globin fusion mRNA (T $\beta G$ ) was described earlier [24]. For in vitro transcription, the plasmid was linearized by digestion at the EcoRI site located downstream to primer annealing place, and RiboMAX kit (Promega) was used. The resulting uncapped transcripts were precipitated with $2 \mathrm{M} \mathrm{LiCl}$, and then ScriptCap Capping System (EPICENTRE Biotechnologies) was used to obtain $\mathrm{m}^{7} \mathrm{G}$ capped transcript, followed by another $\mathrm{LiCl}$ precipitation. Plasmids coded for firefly luciferase directed by either HCV IRES or human $\beta$-actin, LINE-1, Apaf1 or c-myc $5^{\prime}$ UTRs were described earlier [59,60]. $\beta$-actin-Rluc construct was obtained by inserting the human $\beta$-actin $5^{\prime}$ UTR into the pRluc plasmid [59]. For plasmid CAAcl-Fluc preparation, the $\mathrm{GA}(\mathrm{CAA})_{5} \mathrm{GAA}$ leader was fused to a coding region of the cllacZ leaderless construct [61] by PCR with primers CCCATGGTAATACGACTCACTATAGACAACAACAACAACAAGAAATGAGCACAAAAAAGAAACC and GTGGGATCCTCAAGCTGCACTTGTGTTAATG, and the resulting fragment was digested with $\mathrm{Ncol}$ and inserted into pGL3 
vector (Promega). To obtain luciferase encoding mRNAs used for in vitro translation, PCR products were first synthesized from each construct, with the same reverse primer $\left(T_{50} A A C T T G T T T A T T G-\right.$ CAGCTTATAATGG) that introduced a $50 \mathrm{nt}$ long $3^{\prime}$ poly(A) tail, and specific $\mathrm{T} 7$ promoter containing forward primers (for details, see $[59,60,62])$. The transcription was performed as described above, except that either ARCA or ApppG cap analog (both from New England Biolabs) were added into reaction mixture in 5:1 excess to GTP, to perform co-transcriptional capping of the cap-dependent or HCV messages, respectively.

\subsection{Purification of translation initiation components}

eIF2, eIF3, eIF4F, 40S and 60S were purified from HeLa cell extract, eIF1, eIF1A and eIF4A were expressed in E. coli and purified as described [24,63-65]. Purified tRNA $A_{f}^{\text {Met }}$, a kind gift from V. Makhno and Y. Semenkov, was used as initiator tRNA. For aminoacylation, recombinant MetRSase was used [65]. Native human eIF4B was purified from HeLa extract according to [24]. For preparation of recombinant eIF4B proteins, E. coli Rosetta strain was used. Overnight culture was diluted $1: 20$, grown at $37^{\circ} \mathrm{C}$ up to $A_{600} 1.0$ and the gene expression was induced by $0.5 \mathrm{mM}$ IPTG. Cell were grown further for $4 \mathrm{~h}$ at $30{ }^{\circ} \mathrm{C}$, harvested and disrupted by ultrasonic in A100 buffer (20 mM Tris- $\mathrm{HCl} \mathrm{pH} \mathrm{7.5,} 100 \mathrm{mM} \mathrm{KCl,} \mathrm{10 \%} \mathrm{glycerol} \mathrm{and}$ $1 \mathrm{mM}$ DTT). Then $\mathrm{KCl}$ concentration was elevated to $0.5 \mathrm{M}$, the lysate was incubated in ice for $30 \mathrm{~min}$, and debris was precipitated. The cleared lysate was diluted with A100 buffer to decrease $\mathrm{KCl}$ concentration and fractionated by ion-exchange chromatography at phosphocellulose. Proteins eluted at $250-500 \mathrm{mM}$ were collected, dialyzed against the same buffer containing $150 \mathrm{mM} \mathrm{KCl}$, and loaded onto MonoQ 5/5 FPLC column. When KCl gradient 150-500 mM was applied, eIF4B was eluted around $300 \mathrm{mM} \mathrm{KCl}$. It was concentrated with AmiconUltra (Millipore), and $\mathrm{KCl}$ concentration were lowered to $100 \mathrm{mM}$ by dilution with the same buffer containing $50 \mathrm{mM} \mathrm{KCl}$.

\subsection{Assembly and analysis of translation initiation complexes}

$48 \mathrm{~S}$ ribosomal complexes were assembled and analyzed by toeprinting assay as described earlier [24,66]. Briefly, $48 \mathrm{~S}$ complexes were assembled by incubating $0.5 \mathrm{pmol}$ of mRNA for $10 \mathrm{~min}$ at $30{ }^{\circ} \mathrm{C}$ in a $20-\mu \mathrm{l}$ reaction volume that contained the reconstitution buffer (20 mM Tris- $\mathrm{HCl}$ pH 7.5, $110 \mathrm{mM}$ KOAc, $2.5 \mathrm{mM} \mathrm{Mg}(\mathrm{OAc})_{2}$, $0.25 \mathrm{mM}$ spermidine- $\mathrm{HCl}, 1 \mathrm{mM}$ DTT), $0.4 \mathrm{mM}$ GTP and $1 \mathrm{mM}$ ATP, 10 pmol of Met-tRNA ${ }_{\mathrm{Met}}, 2.5 \mathrm{pmol}$ of $40 \mathrm{~S}$ ribosomal subunits and combination of factors (eIF1 (10 pmol), eIF1A (10 pmol), eIF2 ( 5 pmol), eIF3 ( 5 pmol), eIF4A (10 pmol), eIF4F ( 2 pmol) and various amount of eIF4B, as described in the text). For toe-printing, $5^{\prime}$ terminally $\left[{ }^{32} \mathrm{P}\right]$-labeled oligonucleotide $5^{\prime}$ TCACCACCAACTTCTTCCAC $3^{\prime}$ was used. Assembled complexes were analyzed directly by primer extension using AMV RT (Promega) essentially as described [66]. The autoradiogram was obtained with Phosphorimager (Molecular Dynamics) and quantitatively analyzed by ImageQuant software (GE Healthcare).

\subsection{Krebs-2 cells S30 extract and in vitro translation}

S30 extracts were prepared as described in [62]. Translation experiments were performed in a total volume of $10 \mu \mathrm{l}$, which contained $3.5 \mu \mathrm{l}$ of the S30 extract, translation buffer $(20 \mathrm{mM}$ Hepes- $\mathrm{KOH}$ pH 7.6, $1 \mathrm{mM}$ DTT, $0.5 \mathrm{mM}$ spermidine- $\mathrm{HCl}$, $0.6 \mathrm{mM} \mathrm{Mg}\left(\mathrm{CH}_{3} \mathrm{COO}\right)_{2}, 8 \mathrm{mM}$ creatine phosphate, $1 \mathrm{mM}$ ATP, $0.2 \mathrm{mM}$ GTP, $100 \mathrm{mM} \mathrm{KCH}{ }_{3} \mathrm{COO}$ and $25 \mu \mathrm{M}$ of each amino acid), $2 \mathrm{u}$ of RiboLock RNase inhibitor (Fermentas), equimolar mixture of reporter mRNAs (totally $0.5 \mathrm{pmol}$ ) encoded for Fluc and Rluc under control of various leaders, and $2 \mu \mathrm{l}$ of eIF4B or A100 buffer, as indicated. The translation mixture was incubated at $30{ }^{\circ} \mathrm{C}$ for $1 \mathrm{~h}$. The luciferase activities were measured using the Dual Luciferase Assay kit (Promega).

\section{Results}

\section{1. eIF4B wt, S422D and S422E are equally active in $48 \mathrm{~S}$ reconstitution assay}

To analyze effects of the amino acid substitutions that mimic Ser422 phosphorylation, on eIF4B activity in vitro, we obtained four different preparations of the human factor (Fig. 2A). Three of them (wt, S422D and S422E) were recombinant proteins produced in $E$. coli. To avoid any side effect brought about by terminal extensions, we used untagged constructs and purified the proteins by ionexchange and FPCL chromatography (see Materials and Methods). The fourth preparation was native eIF4B obtained from HeLa cell extract with the use of a standard procedure [24], with the last two stages being the same as in the case of the recombinant preparations. We used the native protein as a positive control throughout out study, since earlier we showed the significantly higher activity of such preparation in the $48 \mathrm{~S}$ initiation complex reconstitution assay [24].

It has been shown that the substitutions S422D and S422E positively affected eIF4B activity when these eIF4B mutants were overexpressed in cultured cells [35,51], most probably by increasing its interaction with eIF3 $[49,51,53]$. The latter suggests that such eIF4B variants stimulate protein biosynthesis in cell by direct enhancement of translation initiation complex formation [51]. To test this possibility, we performed a comparison of the four eIF4B variants for their activity in the reaction of $48 \mathrm{~S}$ complex reconstitution from purified components with a model mRNA that harbors rather long and GC-rich 5' UTR. We took the same mRNA $(T \beta G)$ as we had used before in such an assay since it was known to require elevated amount of eIF4B for efficient $48 \mathrm{~S}$ assembly [24]. The mRNA possessed $200 \mathrm{nt}$ long tripartite leader of late adenovirus transcripts fused to the rabbit $\beta$-globin mRNA (Fig. $2 B$ ).

In our initial experiment, we used a concentration of elF4B proteins that had been stated as a standard one for our assay [24] $(10 \mu \mathrm{g} / \mathrm{ml}, \sim 150 \mathrm{nM})$ which corresponds to $\sim 6: 1$ molar ratio of eIF4B to mRNA. The initiation complexes were visualized by toeprinting technique $[24,63,66]$. The results shown in Fig. $2 \mathrm{C}$ confirm our previous observation that eIF4B is absolutely required for $48 \mathrm{~S}$ assembly with this mRNA (compare lines 1 and 2-5) and clearly demonstrate that all three recombinant proteins direct the complex formation with similar efficiency (compare lines 2, 3 and 4). This result indicates that amino acid substitutions S422D and S422E do not affect eIF4B activity in this test. In contrast, the native protein did stimulate $48 \mathrm{~S}$ complex formation more efficiently than any recombinant eIF4B variants (Fig. $2 \mathrm{C}$, line 5 ). To exclude the possibility that this difference is specific for the concentration of the factor we used, we performed the same comparison along the wide range of eIF4B concentration (Fig. 2D). An effect of the amino acid substitutions could not be observed in any case, whereas the native protein clearly possessed significantly higher activity in the whole range of eIF4B concentration tested.

These results suggest that the recombinant eIF4Bs lacked either a proper protein folding or an activating post-translational modification. In the latter case, the negative result might suggest that the amino acid substitutions S422D and S422E do not reproduce such a modification. However, the alternative explanation does exist that the stimulating effect of phosphomimetic substitutions observed in vivo requires additional component(s) lacking in our reconstituted system. 

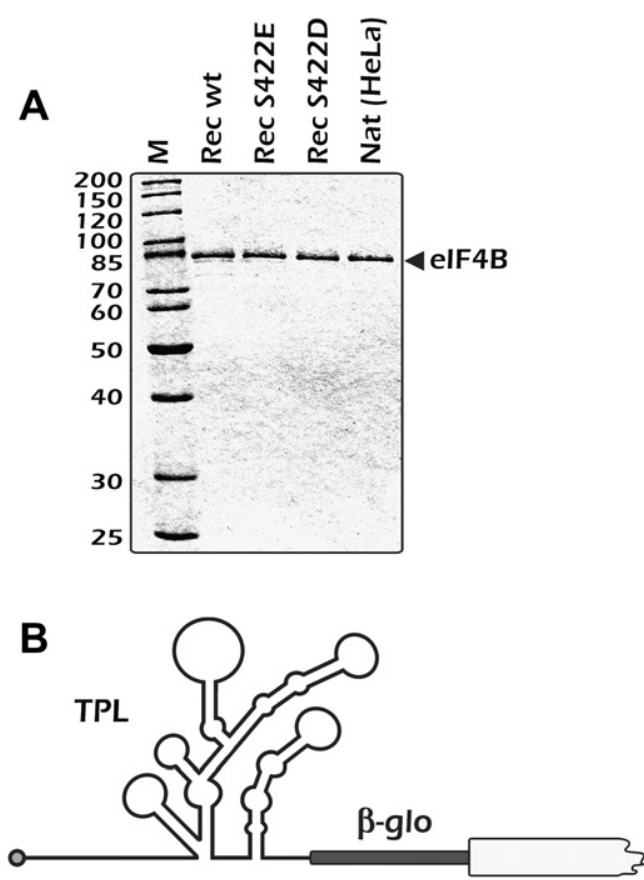

C

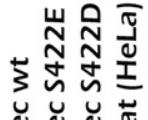

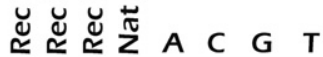

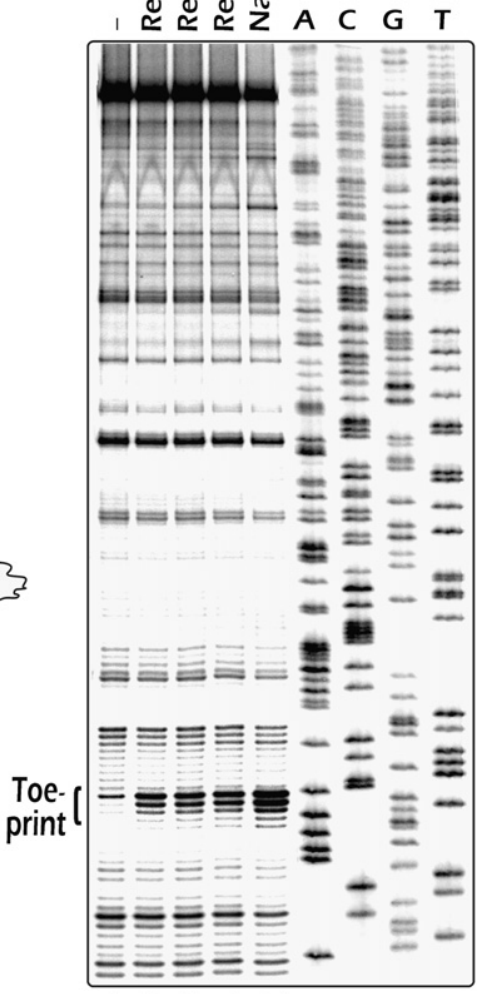

$123 \quad 345$

5

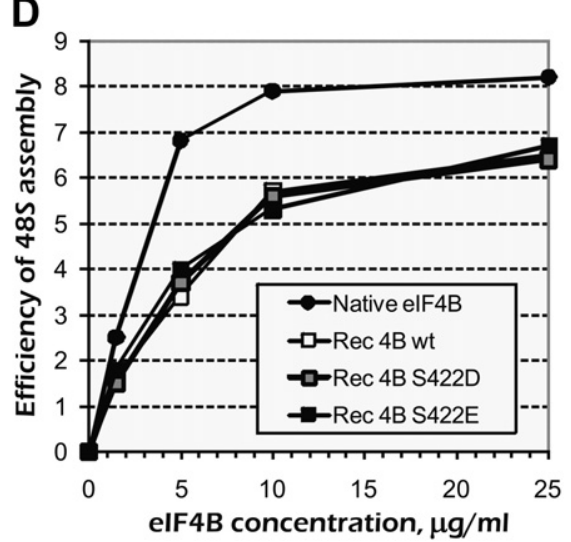

Fig. 2. Activity of the different eIF4B preparations in the $48 \mathrm{~S}$ reconstitution assay. (A) SDS-PAGE of the four different preparation of the human eIF4B used in the study. (B) Schematic representation of the TPL- $\beta$-globin fusion $(T \beta G)$ mRNA. A part of the $5^{\prime}$ UTR that corresponds to the $\beta$-globin leader is represented by the thick line, coding region is shown as the white box. (C) Toe-printing analysis of the $48 \mathrm{~S}$ initiation complex reconstituted on the T $\beta G$ mRNA with different eIF4B preparations. In line 1 , no eIF4B was added. Sequencing lanes obtained with the same primer and the corresponding cDNA are shown on the right. (D) Efficiency of the $48 \mathrm{~S}$ complex assembly on the TBG mRNA at various eIF4B concentrations as revealed by toe-printing. The volumes were obtained by quantification of the toe-print band intensities and dividing them to total intensity in the corresponding lanes. All the experiments were performed in triplicate, with one representative result shown for each case in panels (C) and (D).

\section{2. eIF4B $w t$, S422D and S422E stimulate translation in a complete cell lysate to the same extent}

To exclude the latter possibility, we analyzed effects of the amino acid substitution on eIF4B activity in a cell-free translation system based on a complete cell extract. First, to develop proper experimental conditions, we used a mix of two reporter mRNAs, one of which encoded the firefly luciferase (Fluc) under control of the hepatitis $C$ virus (HCV) internal ribosome entry site (IRES), while the other contained $\mathrm{m}^{7} \mathrm{G}$-capped $5^{\prime} \mathrm{UTR}$ of the human $\beta$-actin mRNA and encoded Renilla luciferase (Rluc). We expected that addition of eIF4B would stimulate the $\beta$-actin mRNA translation, whereas the Fluc luciferase synthesis directed by the HCV IRES would remain at the same level.

In our hands, addition of any of our eIF4B preparations into the conventional rabbit reticulocyte lysate (RRL) inhibited capdependent translation (data not shown). This was not completely unexpected, since RRL had long been known as an inadequate system for studying translation initiation mechanisms (see, for example [62,67],). The same effect of translation repression by eIF4B added into RRL has been observed also by Raught et al. [35] Therefore, in all experiments below we used a cell-free system based on Krebs- 2 ascite cells extract, which more closely reproduces the situation in living cells $[60,62]$.

In this in vitro system, the recombinant wt eIF4B selectively stimulated translation of the capped mRNA possessing the human $\beta$-actin leader (Fig. 3A) while the HCV IRES-directed translation was even slightly inhibited (most likely due to a competition with endogenous cap-dependent mRNAs present in the lysate). The stimulation effect was reproduced also with several other capdependent mRNAs (Fig. 3B). Curiously, in this assay we did not observe any direct correlation of stimulation degree with a level of $5^{\prime}$ UTR secondary structure. Although in the case of an extremely long (906 nt) and GC-rich leader of the human retrotransposon LINE-1 mRNA the degree of translation stimulation by eIF4B was among the highest, the level of stimulation for mRNA containing 

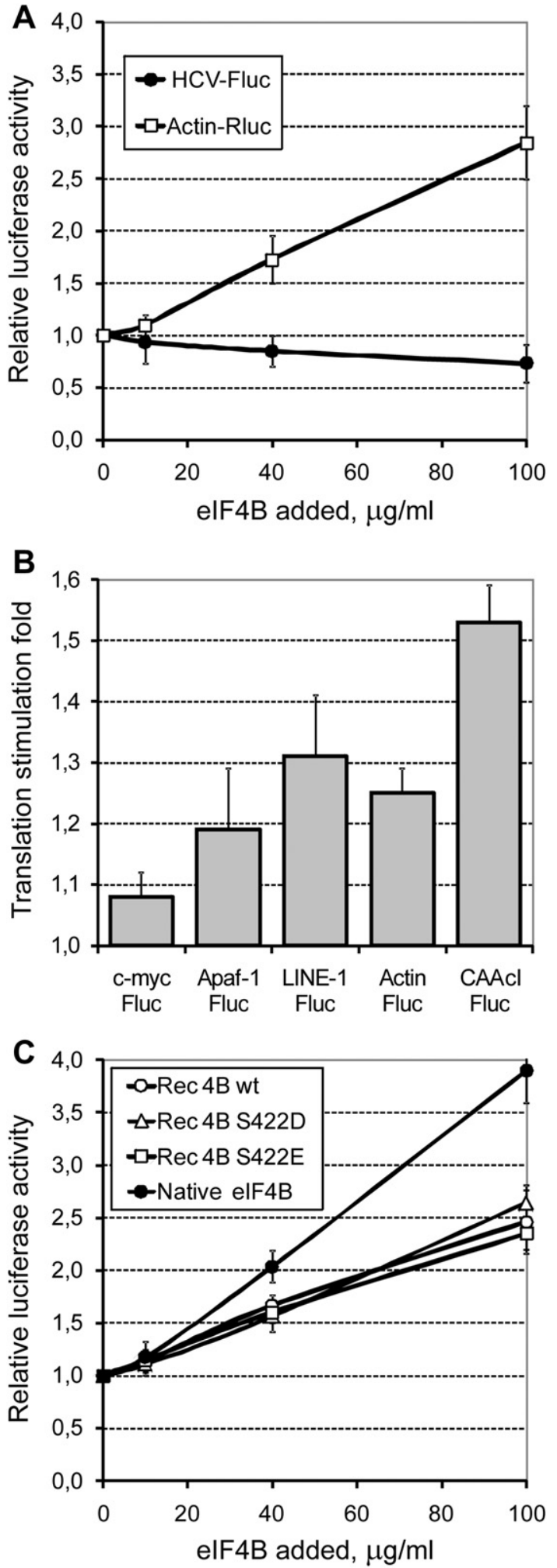

Fig. 3. Effect of different eIF4B preparations on in vitro translation in the complete cell lysate. (A) Differential effect of eIF4B on cap-dependent $v$ s. HCV IRES-dependent translation. Capped Renilla luciferase mRNA driven by the human $\beta$-actin $5^{\prime}$ UTR (Actin-Rluc) and the HCV IRES-directed firefly luciferase mRNA (HCV-Fluc) were translated in the presence of increasing amount of the recombinant eIF4B wt protein. Luciferase activity values were normalized to the values obtained in the absence of exogenous eIF4B. (B) Stimulation of cap-dependent translation of firefly luciferase mRNAs with different leaders by addition of the recombinant eIF4B wt protein $(20 \mu \mathrm{g} / \mathrm{ml})$.(C) Differential effect of eIF4B preparations on in vitro translation of the Actin-Rluc mRNA. the $\beta$-actin leader ( $84 \mathrm{nt}$ long) were close to that of Apaf- $15^{\prime}$ UTR (577 nt) directed mRNA and even higher than that of c-myc $5^{\prime}$ UTR (410 nt) directed one (Fig. 3B). Moreover, the translation of mRNA possessing $(\mathrm{CAA})_{5}$ leader which most likely possesses a singlestranded conformation was stimulated to even a higher extent than that of the LINE-1 $5^{\prime}$ UTR-directed mRNA. The latter was all the more unexpected as mRNAs with the (CAA) $n$ leaders have been shown to possess a relaxed dependence of eIF4 factors and do not require eIF4B for translation initiation in the $48 \mathrm{~S}$ reconstitution system [68]. These observations may suggest that eIF4B function in translation initiation is not limited to assistance in unwinding RNA secondary structure of the leader.

Nevertheless, it should be noted that all cap-dependent mRNAs we tested were stimulated by eIF4B. We therefore examined effects produced by the different eIF4B forms on translation of the Renilla luciferase mRNA with the $\beta$-actin $5^{\prime}$ UTR. As evident from Fig. 3C, all three recombinant proteins stimulated the cap-dependent mRNA translation to the same extent, while the native eIF4B had significantly ( $\sim 1.5$ times) higher activity in this assay. This clearly demonstrates that S422D or S422E is not enough to reproduce the effect of the native protein in the whole cell lysate as well, and excludes the possibility that some unknown cytosolic factor is needed to mediate the stimulatory effect of phosphomimetic Ser422 substitutions observed in vivo.

\section{Discussion}

Human eIF4B has long been known to be a phosphoprotein (for review, see [31]). Several signaling cascades converge on eIF4B phosphorylation, thus underlining its importance in cell response to various stimuli (see Fig. 1). Recently, several groups presented solid evidence that phosphorylation of eIF4B at Ser422 significantly enhances cap-dependent translation in cultured cells by a mechanism that involves modulation of eIF4B affinity to the eIF3 complex $[44,49,51,53]$. According to these data, eIF4B phosphomimetic mutants S422D and S422E were able to reproduce the effects of eIF4B phosphorylation in cultured mammalian cells.

To uncover details of the underlying mechanism, we decided to analyze the activity of eIF4B variants in the system of $48 \mathrm{~S}$ complex reconstitution from purified components [24]. Since homogeneous preparations of differentially phosphorylated recombinant eIF4B molecules could not be obtained in vitro due to an excess of potential modification sites in the protein [69], we used the phosphomimetic mutants S422D and S422E in our analysis.

Previously, in our in vitro system we observed superiority in activity of the eIF4B purified form HeLa cells over the bacterially expressed protein [24]. In the present study, we confirmed this observation. However, all the recombinant eIF4B variants (wt, S422D and S422E) turned out to have the same relatively low activity in the assay (Fig. 2).

Since manifestation of the eIF4B phosphomimetic mutations might require some additional component(s) lacking in our reconstituted system, we performed an analysis of their effects on eIF4B activity in the complete cell-free system based on Krebs-2 ascite cell extract $[60,62]$. In these tests, no difference between the recombinant eIF4B variants were observed as well, although the native eIF4B protein still demonstrated significantly higher activity (Fig. 3).

From these results, one could propose one of the following possibilities. First, S422D and S422E may have not any stimulatory role in eIF4B activity, while the effects reported previously for cultured cells reflected some unrelated events (like elevated eIF4B expression or improved protein stability). Although eIF4B purified from HeLa cells nevertheless showed the superior effect even in vitro, this could be explained simply by its better folding. It 
should be noted, however, that the complete cell lysate we used for in vitro translation should possess all molecular chaperones needed for re-folding of cytosolic proteins during the $1 \mathrm{~h}$ long incubation of the reaction mixture. For this reason, we suggested the first explanation unlikely. However, the higher activity of the native protein may also be explained by some other modification(s) of eIF4B that stimulate its activity independently on phosphorylation of Ser422 (see below). The corresponding modification enzymes activity could be lost during the lysate preparation since many of signaling pathway components are membrane bound proteins.

Then, the effects of S422D and S422E mutations on global protein synthesis observed in vivo could be mediated by some secondary effects. eIF4B phosphorylation at Ser422 may be required for specific activity of the initiation factor toward a certain set of mRNA species. As is clear from our experiments in cell-free translation system (Fig. 3B), the stimulation provided by eIF4B is different for different mRNAs. The phosphorylated factor (or corresponding eIF4B mutants) could have higher activity toward some specific RNA secondary structures located within leaders of a specific set of mRNA species. Thus, being overexpressed in cultured cells it can stimulate production of some regulatory proteins (e.g. components of translational apparatus) which in turn leads to stimulation of global protein synthesis. Such secondary effects could not be analyzed in a cell-free system.

The third explanation is that manifestation of S422D or S422E effects requires some conditions that are only present in intact living cells. These might be specific protein localization to intracellular compartments, interaction with the cytoskeleton or other conditions which are absent from in vitro systems, even from the complete cell lysate. In this case, superiority of the native protein over the three recombinant preparations in our systems may be explained by some other unrelated modifications, as in the first case.

Finally, S422D and S422E may have not any effect on eIF4B activity, until some other, prerequisite modification is applied. Again, such a modification could be present in the native eIF4B preparation.

Thus, our study raises the question on whether the phosphorylation of Ser422 is the sufficient modification for eIF4B activation observed in cultured human cells upon mitogenic stimulation, or at least whether its effect is direct. It is important to note that in the very first study where this particular modification was determined [35], at least one other phosphorylation at Ser was detected that was not dependent on the stimulation by serum. This phosphorylation was not reproduced in vitro by S6K1 treatment. This, or some other modification, could be an indispensable condition for the manifestation of Ser422 phosphorylation effects, or even a prerequisite event for it, being a part of a hierarchical phosphorylation scheme similar to that known for 4E-BP1 (for review, see $[4,70]$ ).

For example, Ser406 was recently determined as a novel major mitogen-regulated phosphorylation site which induction upon insulin treatment was dependent on both MEK and mTOR activity [44]. Ser406 has also been shown to be phosphorylated by proproliferative and pro-survival protein kinase Pim-2 that is thought to regulate the cell cycle in an mTOR independent manner [46]. Interestingly, S406A substitution abrogates stimulatory effect of eIF4B overexpression in vivo similarly to S422A [44]. Although in early work [35] Ser406 was shown to be dispensable for phosphorylation of both Ser422 and the other site (the above mentioned undetermined, serum-independent one), it may nevertheless play an important role in manifestation of their effects in vivo. Similarly, phosphorylation of eIF4B at several additional positions by cell cycle regulated kinase Plk1 that was observed upon arsenic treatment [45], along with many other eIF4B modifications that were found in large-scale proteomic surveys (see http://www.hprd.org) could play a role in eIF4B activation and its modulation by Ser 422 phosphorylation. These questions require additional studies that should involve both in vivo and in vitro analysis.

\section{Acknowledgments}

The authors thank N. Sonenberg (McGill University, Canada) and D. Shahbazian (Yale University, USA) for discussing the results and valuable suggestions. This work was supported by the Russian Foundation of Basic Research (RFBR grant $\mathcal{N} \circ 10-04-01563 a)$ and grant of the President of Russian Federation (MK-5309.2011.4) to S.E.D.

\section{Appendix A. Supplementary material}

Supplementary data associated with this article can be found, in the online version, at http://dx.doi.org/10.1016/j.biochi.2012. 06.021 .

\section{References}

[1] M.B. Mathews, N. Sonenberg, J.W.B. Hershey, Origins and Principles of translational control, in: N.S. Michael, B. Mathews, John W.B. Hershey (Eds.), Translational Control in Biology and Medicine, Cold Spring Harbor Laboratory Press, 2007, pp. $1-40$

[2] N. Sonenberg, A.G. Hinnebusch, Regulation of translation initiation in eukaryotes: mechanisms and biological targets, Cell 136 (2009) 731-745.

[3] D. Ron, H.P. Harding, eIF2alpha phosphorylation in cellular stress responses and disease, in: N. S, Michael B. Mathews, John W.B. Hershey (Eds.), Translational Control in Biology and Medicine, Cold Spring Harbor Laboratory Press, 2007, pp. 345-368

[4] A.C. Gingras, B. Raught, N. Sonenberg, mTOR signaling to translation, Curr. Top. Microbiol. Immunol. 279 (2004) 169-197.

[5] S.C. Milburn, J.W. Hershey, M.V. Davies, K. Kelleher, R.J. Kaufman, Cloning and expression of eukaryotic initiation factor 4B cDNA: sequence determination identifies a common RNA recognition motif, EMBO J. 9 (1990) 2783-2790.

[6] T. Naranda, W.B. Strong, J. Menaya, B.J. Fabbri, J.W. Hershey, Two structural domains of initiation factor eIF-4B are involved in binding to RNA, J. Biol. Chem. 269 (1994) 14465-14472.

[7] R. Benne, J.W. Hershey, The mechanism of action of protein synthesis initiation factors from rabbit reticulocytes, J. Biol. Chem. 253 (1978) 3078-3087.

[8] H. Trachsel, B. Erni, M.H. Schreier, T. Staehelin, Initiation of mammalian protein synthesis. II. The assembly of the initiation complex with purified initiation factors, J. Mol. Biol. 116 (1977) 755-767.

[9] X. Bi, J. Ren, D.J. Goss, Wheat germ translation initiation factor eIF4B affects eIF4A and eIFiso4F helicase activity by increasing the ATP binding affinity of eIF4A, Biochemistry 39 (2000) 5758-5765.

[10] A.R. Ozes, K. Feoktistova, B.C. Avanzino, C.S. Fraser, Duplex unwinding and ATPase activities of the DEAD-box helicase eIF4A are coupled by eIF4G and eIF4B, J. Mol. Biol. 412 (2011) 674-687.

[11] G.W. Rogers Jr., N.J. Richter, W.F. Lima, W.C. Merrick, Modulation of the helicase activity of eIF4A by eIF4B, eIF4H, and eIF4F, J. Biol. Chem. 276 (2001) 30914-30922.

[12] F. Rozen, I. Edery, K. Meerovitch, T.E. Dever, W.C. Merrick, N. Sonenberg, Bidirectional RNA helicase activity of eucaryotic translation initiation factors 4A and 4F, Mol. Cell Biol. 10 (1990) 1134-1144.

[13] N. Methot, M.S. Song, N. Sonenberg, A region rich in aspartic acid, arginine, tyrosine, and glycine (DRYG) mediates eukaryotic initiation factor 4B (eIF4B) self-association and interaction with eIF3, Mol. Cell Biol. 16 (1996) 5328-5334.

[14] M. Bushell, W. Wood, G. Carpenter, V.M. Pain, S.J. Morley, M.J. Clemens, Disruption of the interaction of mammalian protein synthesis eukaryotic initiation factor 4B with the poly(A)-binding protein by caspase- and viral protease-mediated cleavages, J. Biol. Chem. 276 (2001) 23922-23928.

[15] N. Methot, G. Pickett, J.D. Keene, N. Sonenberg, In vitro RNA selection identifies RNA ligands that specifically bind to eukaryotic translation initiation factor 4B: the role of the RNA remotif, RNA 2 (1996) 38-50.

[16] J.A. Grifo, R.D. Abramson, C.A. Satler, W.C. Merrick, RNA-stimulated ATPase activity of eukaryotic initiation factors, J. Biol. Chem. 259 (1984) 8648-8654.

[17] M. Altmann, B. Wittmer, N. Methot, N. Sonenberg, H. Trachsel, The Saccharomyces cerevisiae translation initiation factor Tif3 and its mammalian homologue, eIF-4B, have RNA annealing activity, EMBO J. 14 (1995) 3820-3827.

[18] L. Lindqvist, H. Imataka, J. Pelletier, Cap-dependent eukaryotic initiation factor-mRNA interactions probed by cross-linking. RNA 14 (2008) 960-969.

[19] N. Rozovsky, A.C. Butterworth, M.J. Moore, Interactions between eIF4AI and its accessory factors eIF4B and eIF4H, RNA 14 (2008) 2136-2148.

[20] A. Marintchev, K.A. Edmonds, B. Marintcheva, E. Hendrickson, M. Oberer, C. Suzuki, B. Herdy, N. Sonenberg, G. Wagner, Topology and regulation of the 
human eIF4A/4G/4H helicase complex in translation initiation, Cell 136 (2009) 447-460.

21] A.S. Spirin, How does a scanning ribosomal particle move along the 5'untranslated region of eukaryotic mRNA? Brownian Ratchet model, Biochemistry 48 (2009) 10688-10692.

[22] B.K. Ray, T.G. Lawson, R.D. Abramson, W.C. Merrick, R.E. Thach, Recycling of messenger RNA cap-binding proteins mediated by eukaryotic initiation factor 4B. J. Biol. Chem. 261 (1986) 11466-11470.

[23] K.H. Nielsen, M.A. Behrens, Y. He, C.L. Oliveira, L.S. Jensen, S.V. Hoffmann, J.S. Pedersen, G.R. Andersen, Synergistic activation of eIF4A by eIF4B and eIF4G, Nucleic Acids Res. 39 (2011) 2678-2689.

[24] S.E. Dmitriev, I.M. Terenin, Y.E Dunaevsky, W.C. Merrick, IN Shatsky, Assembly of $48 \mathrm{~S}$ translation initiation complexes from purified component with mRNAs that have some base pairing within their 5' untranslated regions, Mol. Cell Biol. 23 (2003) 8925-8933.

[25] I.B. Rogozin, A.V. Kochetov, F.A. Kondrashov, E.V. Koonin, L. Milanesi, Presence of ATG triplets in 5' untranslated regions of eukaryotic cDNAs correlates with a 'weak' context of the start codon, Bioinformatics 17 (2001) 890-900.

[26] S.F. Mitchell, S.E. Walker, M.A. Algire, E.H. Park, A.G. Hinnebusch, J.R. Lorsch, The 5'-7-methylguanosine cap on eukaryotic mRNAs serves both to stimulate canonical translation initiation and to block an alternative pathway, Mol. Cell 39 (2010) 950-962.

[27] S.A. Shabalina, A.Y. Ogurtsov, I.B. Rogozin, E.V. Koonin, D.J. Lipman, Comparative analysis of orthologous eukaryotic mRNAs: potential hidden functional signals, Nucleic Acids Res. 32 (2004) 1774-1782.

[28] E.W. Wilker, M.A. van Vugt, S.A. Artim, P.H. Huang, C.P. Petersen, H.C. Reinhardt, Y. Feng, P.A. Sharp, N. Sonenberg, F.M. White, M.B. Yaffe, 14-3 3sigma controls mitotic translation to facilitate cytokinesis, Nature 446 (2007) 329-332.

[29] M. Bushell, W. Wood, M.J. Clemens, S.J. Morley, Changes in integrity and association of eukaryotic protein synthesis initiation factors during apoptosis, Eur. J. Biochem. 267 (2000) 1083-1091.

[30] J.W. Hershey, Translational control in mammalian cells, Annu. Rev. Biochem. 60 (1991) 717-755.

[31] D. Shahbazian, A. Parsyan, E. Petroulakis, J. Hershey, N. Sonenberg, eIF4B controls survival and proliferation and is regulated by proto-oncogenic signaling pathways, Cell Cycle 9 (2010) 4106-4109.

[32] D. Shahbazian, A. Parsyan, E. Petroulakis, I. Topisirovic, Y. Martineau, B.F. Gibbs, Y. Svitkin, N. Sonenberg, Control of cell survival and proliferation by mammalian eukaryotic initiation factor 4B, Mol. Cell Biol. 30 (2010) $1478-1485$.

[33] M. Altmann, P.P. Muller, B. Wittmer, F. Ruchti, S. Lanker, H. Trachsel, A Saccharomyces cerevisiae homologue of mammalian translation initiation factor 4B contributes to RNA helicase activity, EMBO J. 12 (1993) 3997-4003.

[34] R. Coppolecchia, P. Buser, A. Stotz, P. Linder, A new yeast translation initiation factor suppresses a mutation in the eIF-4A RNA helicase, EMBO J. 12 (1993) 4005-4011.

[35] B. Raught, F. Peiretti, A.C. Gingras, M. Livingstone, D. Shahbazian, G.L. Mayeur R.D. Polakiewicz, N. Sonenberg, J.W. Hershey, Phosphorylation of eucaryotic translation initiation factor 4B Ser422 is modulated by S6 kinases, EMBO J. 23 (2004) 1761-1769.

[36] T.S. Prasad, K. Kandasamy, A. Pandey, Human protein Reference database and human Proteinpedia as discovery tools for systems biology, Methods Mol. Biol. 577 (2009) 67-79.

[37] R. Benne, J. Edman, R.R. Traut, J.W. Hershey, Phosphorylation of eukaryotic protein synthesis initiation factors, Proc. Natl. Acad. Sci. U S A 75 (1978) $108-112$.

[38] R. Duncan, J.W. Hershey, Heat shock-induced translational alterations in HeLa cells. Initiation factor modifications and the inhibition of translation, J. Biol Chem. 259 (1984) 11882-11889.

[39] R. Duncan, J.W. Hershey, Regulation of initiation factors during translational repression caused by serum depletion. Covalent modification, J. Biol. Chem. 260 (1985) 5493-5497.

[40] R.F. Duncan, J.W. Hershey, Protein synthesis and protein phosphorylation during heat stress, recovery, and adaptation, J. Cell Biol. 109 (1989) 1467-1481.

[41] G.A. Floyd, W.C. Merrick, J.A. Traugh, Identification of initiation factors and ribosome-associated phosphoproteins by two-dimensional polyacrylamide gel electrophoresis, Eur. J. Biochem. 96 (1979) 277-286.

[42] D.R. Gallie, H. Le, C. Caldwell, R.L. Tanguay, N.X. Hoang, K.S. Browning, The phosphorylation state of translation initiation factors is regulated developmentally and following heat shock in wheat, J. Biol. Chem. 272 (1997) 1046-1053.

[43] H. Le, K.S. Browning, D.R. Gallie, The phosphorylation state of the wheat translation initiation factors eIF4B, eIF4A, and eIF2 is differentially regulated during seed development and germination, J. Biol. Chem. 273 (1998) 20084-20089.

[44] A.G. van Gorp, K.E. van der Vos, A.B. Brenkman, A. Bremer, N. van den Broek, F. Zwartkruis, J.W. Hershey, B.M. Burgering, C.F. Calkhoven, P.J. Coffer, AGC kinases regulate phosphorylation and activation of eukaryotic translation initiation factor 4B, Oncogene 28 (2009) 95-106.

[45] Y.J. Chen, Y.P. Lin, L.P. Chow, T.C. Lee, Proteomic identification of Hsp70 as a new Plk1 substrate in arsenic trioxide-induced mitotically arrested cells, Proteomics 11 (2011) 4331-4345.
[46] C. Peng, A. Knebel, N.A. Morrice, X. Li, K. Barringer, J. Li, S. Jakes, B. Werneburg, L. Wang, Pim kinase substrate identification and specificity, J. Biochem. 141 (2007) 353-362.

[47] J.M. Manzella, W. Rychlik, R.E. Rhoads, J.W. Hershey, P.J. Blackshear, Insulin induction of ornithine decarboxylase. Importance of mRNA secondary structure and phosphorylation of eucaryotic initiation factors eIF-4B and eIF-4E, J. Biol. Chem. 266 (1991) 2383-2389.

[48] S.J. Morley, J.A. Traugh, Differential stimulation of phosphorylation of initiation factors eIF-4F, eIF-4B, eIF-3, and ribosomal protein S6 by insulin and phorbol esters, J. Biol. Chem. 265 (1990) 10611-10616.

[49] D. Shahbazian, P.P. Roux, V. Mieulet, M.S. Cohen, B. Raught, J. Taunton, J.W. Hershey, J. Blenis, M. Pende, N. Sonenberg, The mTOR/PI3K and MAPK pathways converge on eIF4B to control its phosphorylation and activity, EMBO J. 25 (2006) 2781-2791.

[50] R.M. Wolthuis, A.F. Cremers, M.A. Kasperaitis, C. van der Mast, H.O. Voorma J. Boonstra, Epidermal growth factor stimulates phosphorylation of eukaryotic initiation factor 4B, independently of protein kinase C, Biochim. Biophys. Acta 1177 (1993) 160-166.

[51] M.K. Holz, B.A. Ballif, S.P. Gygi, J. Blenis, mTOR and S6K1 mediate assembly of the translation preinitiation complex through dynamic protein interchange and ordered phosphorylation events, Cell 123 (2005) 569-580.

[52] B. Kroczynska, S. Joshi, E.A. Eklund, A Verma, S.V. Kotenko, E.N. Fish, L.C. Platanias, Regulatory effects of ribosomal S6 kinase 1 (RSK1) in IFNlambda signaling, J. Biol. Chem. 286 (2011) 1147-1156.

[53] B. Kroczynska, S. Kaur, E. Katsoulidis, B. Majchrzak-Kita, A. Sassano, S.C. Kozma, E.N. Fish, L.C. Platanias, Interferon-dependent engagement of eukaryotic initiation factor 4B via S6 kinase (S6K)- and ribosomal protein S6Kmediated signals, Mol. Cell Biol. 29 (2009) 2865-2875.

[54] Y.H. Shen, B.R. Chen, S.H. Cherng, P.J. Chueh, X. Tan, Y.W. Lin, J.C. Lin S.M. Chuang, Cisplatin transiently up-regulates hHR23 expression through enhanced translational efficiency in A549 adenocarcinoma cells, Toxicol. Lett. 205 (2011) 341-350

[55] Y. Zhang, Q. Wang, X. Guo, R. Miller, Y. Guo, H.S. Yang, Activation and upregulation of translation initiation factor $4 \mathrm{~B}$ contribute to arsenic-induced transformation, Mol. Carcinog. 50 (2011) 528-538.

[56] E. Kuang, B. Fu, Q. Liang, J. Myoung, F. Zhu, Phosphorylation of eukaryotic translation initiation factor $4 \mathrm{~B}$ (EIF4B) by open reading frame 45/p90 ribosomal S6 kinase (ORF45/RSK) signaling axis facilitates protein translation during Kaposi sarcoma-associated herpesvirus (KSHV) lytic replication, J. Biol Chem. 286 (2011) 41171-41182.

[57] D. Kumar, S. Konkimalla, A. Yadav, K. Sataranatarajan, B.S. Kasinath, P.N. Chander, P.C. Singhal, HIV-associated nephropathy: role of mammalian target of rapamycin pathway, Am. J. Pathol. 177 (2010) 813-821.

[58] A. Pause, N. Sonenberg, Mutational analysis of a DEAD box RNA helicase: the mammalian translation initiation factor eIF-4A, EMBO J. 11 (1992) 2643-2654.

[59] S.E. Dmitriev, D.E. Andreev, I.M. Terenin, I.A. Olovnikov, V.S. Prassolov, W.C. Merrick, I.N. Shatsky, Efficient translation initiation directed by the $900-$ nucleotide-long and GC-rich 5' untranslated region of the human retrotransposon LINE-1 mRNA is strictly cap dependent rather than internal ribosome entry site mediated, Mol. Cell Biol. 27 (2007) 4685-4697.

[60] D.E. Andreev, S.E. Dmitriev, I.M. Terenin, V.S. Prassolov, W.C. Merrick I.N. Shatsky, Differential contribution of the m7G-cap to the 5' end-dependent translation initiation of mammalian mRNAs, Nucleic Acids Res. 37 (2009) 6135-6147.

[61] D.E. Andreev, I.M. Terenin, Y.E. Dunaevsky, S.E. Dmitriev, I.N. Shatsky, A leaderless mRNA can bind to mammalian 80S ribosomes and direct polypeptide synthesis in the absence of translation initiation factors, Mol. Cell Biol. 26 (2006) 3164-3169.

[62] S.E. Dmitriev, D.E. Andreev, Z.V. Adyanova, I.M. Terenin, I.N. Shatsky, Efficient cap-dependent translation of mammalian mRNAs with long and highly structured 5'-untranslated regions in vitro and in vivo, Mol. Biol. (Mosk) 43 (2009) 108-113.

[63] T.V. Pestova, C.U. Hellen, I.N. Shatsky, Canonical eukaryotic initiation factors determine initiation of translation by internal ribosomal entry, Mol. Cell Biol. 16 (1996) 6859-6869.

[64] T.V. Pestova, S.I. Borukhov, C.U. Hellen, Eukaryotic ribosomes require initiation factors 1 and 1 A to locate initiation codons, Nature 394 (1998) 854-859.

[65] I.M. Terenin, S.E. Dmitriev, D.E. Andreev, E. Royall, G.J. Belsham, LO. Roberts, I.N. Shatsky, A cross-kingdom internal ribosome entry site reveals a simplified mode of internal ribosome entry, Mol. Cell Biol. 25 (2005) 7879-7888.

[66] S.E. Dmitriev, A.V. Pisarev, M.P. Rubtsova, Y.E. Dunaevsky, I.N. Shatsky, Conversion of $48 \mathrm{~S}$ translation preinitiation complexes into $80 \mathrm{~S}$ initiation complexes as revealed by toeprinting. FEBS Letters 533 (2003) 99-104.

[67] S.E. Dmitriev, N.V. Bykova, D.E. Andreev, I.M. Terenin, Adequate system for investigation of translation initiation of the human retrotransposon L1 mRNA in vitro, Mol. Biol. (Mosk) 40 (2006) 20-24.

[68] T.V. Pestova, V.G. Kolupaeva, The roles of individual eukaryotic translation initiation factors in ribosomal scanning and initiation codon selection, Genes Dev. 16 (2002) 2906-2922.

[69] P.T. Tuazon, W.C. Merrick, J.A. Traugh, Comparative analysis of phosphorylation of translational initiation and elongation factors by seven protein kinases, J. Biol. Chem. 264 (1989) 2773-2777.

[70] C.G. Proud, mTOR-mediated regulation of translation factors by amino acids, Biochem. Biophys. Res. Commun. 313 (2004) 429-436. 